\title{
MAPEANDO O TRÁFICO TRANSATLÂNTICO DE ESCRAVOS
}

\author{
ELTIS, David, e RICHARDSON, David. Atlas of the Transatlantic Slave \\ Trade. New Haven \& Londres: Yale University Press, 2010. 307 p.
}

$D_{\text {avid Eltis e David Richardson têm }}$ dedicado grande parte de suas carreiras a quantificar e entender o tráfico atlântico de africanos em sua complexidade. Um primeiro passo nesse sentido foi o lançamento, em 1999, de um banco de dados contendo informações sobre milhares de viagens negreiras. ${ }^{1}$ Anos mais tarde, os autores disponibilizaram ao público uma versão online mais atualizada desses dados, o Transatlantic Slave Trade Database, resultado do esforço coletivo de dezenas - provavelmente centenas - de historiadores ao redor do mundo. ${ }^{2}$ Nesse site encontram-se dados quantitativos, mas também qualitativos. Entre os primeiros, sobressaem estimativas sobre o tráfico negreiro do século XVI ao XIX, por portos de embarque e desembarque;

1 David Eltis, Stephen Behrendt, David Richardson e Herbert Klein, The Transatlantic Slave Trade, 1527-1867: A Database on CD-ROM, New York: Cambridge University Press, 1999.

2 Disponível em www.slavevoyages.org entre os dados qualitativos, que podem ser acessados individualmente, estão nomes do barco, do capitão e do dono, apenas a título de exemplo. Em 2008, Eltis e Richardson organizaram um livro em que discutem algumas informações encontradas no banco de dados online. ${ }^{3}$ Agora, nos brindam com o Atlas of the Transatlantic Slave Trade, obra cujas páginas são fartamente ilustradas com centenas de mapas, imagens e documentos relacionados ao tráfico. É um livro dedicado à memória de Philip Curtin, historiador recentemente falecido, cuja contribuição para o estudo do tráfico de escravos inspirou a criação do banco de dados das viagens negreiras. ${ }^{4}$

A organização do livro é bastante simples, o Atlas está dividido em seis

3 David Eltis e David Richardson (orgs.), Extending the Frontiers: Essays on the New Transatlantic Slave Trade Database, New Haven e Londres: Yale University Press, 2008.

4 Ver Philip Curtin, The Atlantic Slave Trade: A Census, Madison: University of Wisconsin Press, 1969. 
partes. No início de cada parte, os autores fazem um breve texto explicando o conteúdo do capítulo, antes de adentrarem os mapas. A esmagadora maioria das informações contidas no livro foi retirada do banco de dados em sua versão 2008, com quase 35.000 registros de viagens negreiras.

O livro começa com o prefácio de David Brion Davis, autor de obras célebres sobre a escravidão. Para esse autor, "é difícil compreender o tráfico de escravos e o sistema escravista atlântico que ele criou sem uma coleção altamente detalhada de mapas" (p. xviii). Eis, portanto, a razão pela qual essa obra é tão bem-vinda. Algumas pequenas imprecisões, no entanto, são encontradas em seu prefácio. Por exemplo, Davis relata a lei inglesa de 1788 como se fosse a primeira a regulamentar o número máximo de africanos que poderiam ser carregados pelas embarcações, mas não menciona a lei portuguesa de arqueação de 1684, reiterada em 1719. Trata-se de deslize típico da historiografia do tráfico no hemisfério norte, em que a maioria dos autores desconhecem ou pouco conhecem o que se passava no Atlântico Sul.

A introdução fornece uma visão geral do tráfico no período entre 1501 e 1867, e da construção do complexo escravista nas Américas. Eles discutem o papel da cana-de-açúcar, como o carro chefe dessa economia baseada no trabalho forçado africano, e a importância das correntes marítimas para o tráfico transatlântico de escravos - fato observado, entre nós, por Luiz Felipe de Alencastro. ${ }^{5}$ Por fim, analisam as principais regiões de onde os mais de 12 milhões de africanos foram retirados na África e o locais onde os mais de 10 milhões que sobreviveram à travessia desembarcaram nas Américas. Todas essas informações são representadas através de mapas, acompanhados de pequenos textos que auxiliam sua compreensão.

A primeira parte do livro informa sobre o envolvimento das nações europeias no comércio negreiro. No século XVI e durante a primeira metade do século XVII, portugueses e espanhóis dominaram o tráfico de africanos. A partir de 1660, eles perderam a primazia para outras nações - ingleses e holandeses, principalmente. $\mathrm{O}$ século XVIII foi o período de maior competição, com os ingleses - os mais bem sucedidos neste período em número de escravos transportados -dominando o negócio no Atlântico Norte em direção aos complexos açucareiros no Caribe, enquanto os portugueses mantinham a hegemonia no Atlântico Sul, fundados em sua colônia em Angola e em portos do Golfo do Benim. Os mapas 15 a 21 apresentam o tráfico dos portugueses, brasíli-

\footnotetext{
Luis Felipe de Alencastro, $O$ trato dos viventes: formação do Brasil no Atlântico Sul, séculos XVI e XVII, São Paulo: Companhia das Letras, 2000.
} 
cos (mais tarde dos brasileiros), ingleses, neerlandeses e franceses, entre outros. O mapa 16, por exemplo, dá uma noção mais precisa da extensão do tráfico para o Brasil. Entre 1526 e 1867 , quase cinco milhões de africanos aqui desembarcaram.

A parte II é uma das mais interessantes de todo o Atlas, pois relaciona os principais portos responsáveis pelo comércio de escravos. Graças a isso, sabemos, por exemplo, que $93 \%$ das viagens negreiras saíram de vinte principais portos, sendo Rio de Janeiro e Salvador os mais importantes, seguidos por Liverpool. Os mapas desse capítulo ajudam a visualizar a participação das diversas nações durante a vigência do trato de africanos. Isso possibilita ao leitor ter a dimensão da organização e crescimento desse comércio no decorrer de mais de três séculos.

Alguns desses mapas permitem pensar o tráfico para a Bahia, sobretudo no período da ilegalidade. No mapa 49, Eltis e Richardson apresentam uma projeção do tráfico a partir do porto de Salvador entre 1808 e 1851 . Os autores observam que, não obstante a proibição desse comércio ao norte do Equador em 1817-18, os traficantes continuaram realizando negócios com o Golfo do Benim, local preferencial de aquisição de cativos pelos baianos. Para burlar a lei antitráfico, os traficantes utilizaram diferentes artifícios. $\mathrm{O}$ recurso mais comum era solicitar passaportes para viagens em direção à Molembo, na África Centro Ocidental, quando o real destino dessas embarcações era a África Ocidental. Logo, sabendo que a proibição não diminuiu o ímpeto dos tratantes nessa região africana, o número de escravos retirados da África Centro Ocidental para Bahia - 219.000 - parece superestimado para esse período. Praticamente no mesmo período (18081856), o Rio de Janeiro recebeu 1.047.000 africanos, sendo a esmagadora maioria da região de Angola. Número também significativo veio dos portos da África Oriental, notadamente Moçambique, que foi puxado para o tráfico no século XIX. Segundo o banco de dados, os traficantes cariocas desembarcaram quase 269.000 africanos orientais no porto do Rio de Janeiro durante esse período.

A conexão entre os principais portos de embarque na África e desembarque nas Américas é o objeto da terceira parte do livro. Mais de quatro em cada cinco africanos que atravessaram o Atlântico passaram pelos vinte principais portos de embarque na costa africana, dos quais metade forneceu quase dois terços dos escravos para o tráfico atlântico. Alguns desses portos são bastante conhecidos pelos historiadores brasileiros, como Luanda, por onde foram deportados 2.826.000 africanos, ou Ouidah, de onde partiram 1.004 .000 pessoas, entre 1501 e 1867. O padrão de dis- 
tribuição desses africanos estava longe de ser aleatório; obedecia a interesses nacionais e redes comerciais estabelecidas nos dois lados do Atlântico, como apontou John Thornton. ${ }^{6}$

Os mapas 69 a 71 são de especial interesse para os historiadores da escravidão na Bahia, pois apresentam as fronteiras políticas e linguísticas da Costa do Ouro e do Golfo do Benin em 1650, 1750 e 1850. No que diz respeito ao tráfico baiano, após a tomada de Ouidah pelo Daomé, em 1727, a Bahia recebeu grande número de escravos embarcados neste porto. Surpreendentemente, no período que cobre 1727-1863, a ilha de Saint Domingue (mais tarde Haiti) recebeu número maior de escravos vindos de Ouidah. Naturalmente, a demanda baiana era suprida por outros portos do Golfo do Benin, como Lagos e Porto Novo (mapas 78 e 82).

As fronteiras políticas e linguísticas da África Centro Ocidental, entre 1526 e 1867, são descritas nos mapas 92, 93 e 94. As ligações entre o Brasil e Angola ficam mais evidentes a partir da leitura do mapa 100. Os três principais portos brasileiros (Rio de Janeiro, Salvador e Recife) responderam juntos por 77,2\% dos 2.826 .000 africanos deportados por Luanda. No caso de Molembo (mapa 102), entre 1808 e 1861, 62.000 africanos teriam sido

John Thornton, A África e os africanos na formação do mundo atlântico, 1400-1800, Rio de Janeiro: Elsevier, 2004. exportados para a Bahia, contra 11.000 para o Rio e menos de 10.000 para Pernambuco. Tais dados, no entanto, precisam de uma análise cuidadosa, sob pena de cairmos nos ardis dos traficantes do século XIX, como expliquei acima. Por fim, os mapas 107 a 111 fornecem uma visão geral da África Oriental. O Rio de Janeiro foi o porto que mais recebeu gente dessa região, 126.000 , ou 43\%, seguido por Havana, que recebeu 32.000 pessoas, e Saint Domingue, com 23.000 africanos.

Se a parte II do livro é a mais impressionante em termos de números, a parte IV é, sem dúvida, aquela que melhor retrata a experiência humana da travessia atlântica. Logo no início, Eltis e Richardson afirmam, para lamento dos historiadores brasileiros, que "poucos dados têm sobrevivido para o Brasil" no que diz respeito à idade e gênero no tráfico transatlântico de escravos (p. 159). Entretanto, uma pesquisa mais detalhada em outros documentos não usados pelos autores, como os registros de óbitos - que muitas vezes informam sobre a idade dos africanos falecidos na travessia -, inventários, especialmente de capitães negreiros, registros batismais e alguns censos locais poderiam oferecer maiores informações. De todo modo, a partir dos dados disponíveis para a América do Norte, os autores chegam a três importantes conclusões: as mulheres formaram a mai- 
oria dos deportados antes de 1710; a razão entre adultos e crianças variou enormemente de acordo com as regiões africanas; e a proporção de homens e crianças deportados da África cresceu com o passar dos anos. Quanto à mortalidade, temos maiores informações disponíveis. No tráfico brasileiro, a menor taxa de mortalidade vinha dos navios que navegavam do Golfo do Benim (10\%), e a maior foi encontrada nas embarcações que chegavam da África Oriental (22\%), provavelmente em vista do maior tempo da viagem, 65 dias.

No que diz respeito aos padrões de resistência, o banco de dados registra revoltas a bordo dos navios em apenas 2\% dos casos (600 registros). Entretanto, Eltis e Richardson estimam que um em cada dez navios experimentou algum tipo de rebelião ou sofreu algum ataque na costa africana. Desses 2\%, em apenas 26 casos os africanos comandaram as embarcações de volta à África. O século XVIII foi o período que assistiu o maior número de revoltas e estas foram mais frequentes nos navios que navegavam a norte do Equador. Os autores não possuem uma resposta clara para a localização regional dessas rebeliões; quanto à concentração no Setecentos, argumentam que, antes de 1650, os navios carregavam uma tripulação proporcionalmente maior em relação ao número de escravos a bordo. Após 1810, carrega- vam um número maior de crianças, mais facilmente controláveis do que os adultos. O mapa 132 mostra que apenas $22,5 \%$ das revoltas ocorreram durante a travessia do Atlântico. A grande maioria das rebeliões ocorreu ainda no litoral africano.

A Parte V do livro analisa a distribuição dos desembarques nas diferentes regiões das Américas. Seis em cada dez cativos alcançaram as Américas através de seus sete principais portos. Rio de Janeiro e Salvador aparecem nas primeiras posições dessa funesta lista, seguidos do Recife, Kingston (Jamaica), Bridgetown (Barbados), Havana e Saint Domingue. Mais ainda: três quartos dos cativos chegaram através de apenas vinte portos. Há ainda o tráfico intra-americano, conhecido entre nós como a "terceira perna do tráfico". Um em cada quatro africanos que sobreviveram à travessia do Atlântico teve de enfrentar uma jornada adicional até seu derradeiro destino. Apesar do Rio de Janeiro superar Salvador como principal porto negreiro das Américas, essa primazia só aconteceu no século XIX. Até 1790, Salvador superava o Rio de Janeiro nas chegadas de africanos, como mostram os mapas 171 e 172 , mas um grande número dos escravos que aí desembarcavam, principalmente no século XVIII, seguia para Minas Gerais via Rio de Janeiro.

Esse capítulo, por sinal, apresenta pequenas biografias de personagens 
que atravessaram o Atlântico, alcançaram as Américas e sobreviveram tempo suficiente para adquirir a liberdade e contar suas histórias. É o caso de Venture Smith (p.209), Abaché [Clara Turner], Cudjoe Kazoola Lewis (p. 221), Mahommah Gardo Baquaqua (p. 263), dentre outros.

David Eltis e David Richardson analisam na sexta parte da obra as medidas para a abolição do tráfico de escravos. Naturalmente, os autores dão ênfase às atividades britânicas de repressão ao comércio - embora admitam que a maioria delas não obteve sucesso -, negligenciando as medidas de outras nações, como o Brasil. Mas sejamos justos: afinal, o Atlas tem como principal preocupação apresentar os mapas, baseados nos números das viagens, e não fazer uma discussão mais ampla sobre a extinção do tráfico negreiro.

O tráfico brasileiro foi um dos mais duradouros, e o mapa 183 mostra toda a sua força. Em apenas quatro anos (1836-1840), o porto do Rio de Janeiro recebeu ilegalmente 209.000 africanos, seguido por Cuba (104.000), Pernambuco (27.000) e Bahia (18.000). Nem todos os africanos concluíram a travessia no século XIX por terem sido resgatados pela marinha inglesa, na sua maioria embarcados no Golfo do Benim entre 1808 e 1840. De 1840 até a supressão definitiva do tráfico, na década de 1860, a África Centro Ocidental foi a principal fonte de africanos liberados, com 63,7\% (mapas 187 e 188). Quatro de cada cinco africanos liberados nos negreiros após 1807 foram levados para colônias britânicas, boa parte deles ficando em Serra Leoa.

O historiador David Blight fecha o livro com um belíssimo posfácio. Tomando como ponto de partida sua visita ao Castelo de São Jorge da Mina, em Gana - símbolo da presença europeia no tráfico -, Blight passa em revista os principais temas do Atlas. Mesmo reconhecendo a importância dessa obra, o autor observa, no entanto, que a força e a beleza dos mapas mascaram o horror do tráfico transatlântico de escravos.

Devo concordar com Blight. Atlas of the Transatlantic Slave Trade é uma obra fundamental para todos interessados na história do tráfico negreiro e da diáspora africana. Caberia, porém, não perder de vista a dimensão humana do drama enfrentado pelos milhões de africanos que fizeram a travessia atlântica, muitos dos quais não conseguiram sobreviver a ela, e isso não pode ser avaliado em números. Apesar desse horror, quase 11 milhões de africanos fizeram das Américas seu novo lar, aqui criando expectativas e fixando memórias, e em geral desempenhando papel inestimável na construção do mundo atlântico.

Carlos Silva Jr. Doutorando da Universidade de Hull, Reino Unido 